\title{
STRATIFICATION OF CLINICAL SURVEY DATA USING CONTINGENCY TABLES
}

\author{
Suzan Arslanturk ${ }^{1}$, Mohammad-Reza Siadat ${ }^{1}$, Theophilus Ogunyemi ${ }^{2}$, Brendhan \\ Givens ${ }^{1}$, Ananias Diokno ${ }^{3}$ \\ ${ }^{1}$ Dept of Comp Science and Engineering, \\ Oakland University, Rochester, MI 48309, USA \\ ${ }^{2}$ Department of Mathematics and Statistics, \\ Oakland University, Rochester, MI 48309, USA \\ ${ }^{3}$ Beaumont Health System, \\ William Beaumont Hospital, Royal Oak, MI 48073, USA
}

\begin{abstract}
Data stratification is the process of partitioning the data into distinct and non-overlapping groups since the study population consists of subpopulations that are of particular interest. In clinical data, once the data is stratified into sub populations based on a significant stratifying factor, different risk factors can be determined from each subpopulation. In this paper, the Fisher's Exact Test is used to determine the significant stratifying factors. The experiments are conducted on a simulated study and the Medical, Epidemiological and Social Aspects of Aging (MESA) data constructed for prediction of urinary incontinence. Results show that, smoking is the most significant stratifying factor of MESA data, showing that the smokers and non-smokers indicates different risk factors towards urinary incontinence and should be treated differently.
\end{abstract}

\section{KEYWORDS}

Contingency Tables, Medical Survey Data, Stratification, Subgroup Analysis

\section{INTRODUCTION}

In clinical survey data, it is common for subjects to have their own unique set of answers to the questionnaire. However, the subjects can be grouped into populations based on common answers to specific questions. It is important to divide the dataset into sub-populations based on these questions that have common answers for each population. This will help us to investigate heterogeneous results, or to answer specific questions about particular patients groups and to see whether and how risk factors vary across sub populations. This approach leads us to extract maximum amount of information from the data and gives the clinicians the possibility to apply different treatments for different groups of people. It is important based on what questions to divide (stratify) the population into groups, which we will refer as the stratifying factors throughout this paper. This study proposes a method that shows how to stratify a population based on a simulated study and a longitudinal clinical survey data.

DOI : $10.5121 /$ ijdkp.2014.4401 
A survey data may instruct a respondent to skip some irrelevant questions based on the answer to a previous branching question. A branching question precedes sets of alternative questions and its response determines which alternative set of questions to be answered by a respondent. The questions in the unvisited alternative paths are referred to as skip patterns. Leaving a question unanswered about number of cigarettes smoked by a non-smoker respondent when the questionnaire instructs such person to skip this question is an example of a skip pattern. When the dataset of interest contains skip patterns, it is important to stratify the data based on the branching questions in order to evaluate each stratum independently.

Su et al. have focused on a comparative study where two or more treatments are compared and how the treatment effect varies across subgroups induced by covariates. Treatment effect can be defined as the amount of change in a condition or symptom because of receiving a treatment compared to not receiving the treatment. They have considered a binary treatment effect ( 0 or 1$)$, a continuous output and a number of covariates where the components are of mixed types (categorical and continuous). They have used a tree-structured subgroup analyses algorithm since; the tree algorithm is a well-known tool for determining the interactions between the treatment and the covariates. Their goal in subgroup analysis is to find out whether there exist subgroups of individuals in which the treatment shows heterogeneous effects, and if so, how the treatment effect varies across them. By recursively partitioning the data into two subgroups that show the greatest heterogeneity in the treatment effect, they were able to optimize the subgroup analyses. They have used simulated studies to validate their approach. Also, they have used the Current Population Survey (CPS) database conducted by the U.S Census Bureau for the Bureau of Labor and Statistics, in 2004. The CPS is a survey data of 60.000 households. The investigators were interested in specific subgroups of the working population where the pay gap between sexes is dominant. The questions in the survey were related to some demographic characteristics of the respondents, the employment status, hours worked and the income earned from their work. There were different covariates in the data such as gender, age, education, race, citizenship, tax status, etc. The results show that for most of the subgroups that constitute the majority of the population, women are paid significantly less than men. Also, the wage disparity between men and women varies with the industry, occupation and age. In our study, on the other hand, instead of recursively partitioning the data into sub populations, we are using the branching questions leading the skip patterns to occur as our stratifying factor.

Subgroup analyses are a highly subjective process since the subgroups themselves as well as the number of subgroups are determined by the investigator beforehand (Assmann et al. 2000). It is important to determine which specific subgroup to use in the experiment. The incorrect selection of the subgroups may cause unreliable results. Therefore, significance testing is a common approach in subgroup analyses. That is, testing the numerous plausible possibilities to see which subgroup performs better. However, this approach cannot be considered as an efficient way of splitting the data. We are utilizing the wisdom of experts embedded in the data through the questionnaire design processes when selecting the branching questions as stratifying factors. There have been several studies on determining variables that are important for understanding the underlying phenomena of interest. It is important to reduce the dimension of original data prior to any modeling. Different attribute selection techniques have been used in order to reduce the dimensionality and the computational complexity (Azhagusundari et al.). The attributes that are significant can be extracted, ranked and weights can be assigned to each attribute to compare the significance. Decision trees based on information gain techniques have been widely used in order to perform feature selection. Decision trees divide the population into subgroups recursively until the leaf nodes represents the class labels. However, in this 
International Journal of Data Mining \& Knowledge Management Process (IJDKP) Vol.4, No.4, July 2014

study the feature selection techniques cannot be directly used in order to determine the significant branching questions, since the class labels of individual subject is irrelevant. Instead high support and confidence for prospective extracted rules from each stratum is of interest. That is, a population with mixed class labels in a stratum would be favorable as long as it lends itself to rules with high confidence factor and support. For instance, smoking could be a significant branching question if the rules applied to smokers are different than those applied to nonsmokers. However, there could be populations with mixed class labels in smokers and nonsmokers groups.

Risk stratification in clinical data is used to divide patients into different acuity levels and to determine a person's risk for suffering a particular condition and the need for preventive intervention. Haas et. al have used several risk stratification techniques to evaluate the performance in predicting healthcare utilization. They have studied 83 patients empanelled in 2009 and 2010 in a primary care practice. 7 different risk stratification techniques were used: Adjusted Clinical Groups (ACGs), Hierarchical Condition Categories (HCCs), Elder Risk Assessment, Chronic Co morbidity Count, Charlson Co morbidity Index, and Minnesota Health Care Home Tiering and a combination of Minnesota Tiering and ERA. To predict the healthcare utilization and cost, historical data (data from 2009) have been used by a logistic regression model using demographic characteristics and diagnosis such as emergency department visits, hospitalizations, 30 day readmissions. The results show that ACG model outperforms the other risk stratification methods. They have studied data stratification based on the acuity of each patient and generated different results for each stratum. However, in our study the stratifying factor is unknown beforehand and needs to be determined from the existing branching questions by using statistical methods.

The Medical, Epidemiological and Social Aspects of Aging (MESA) data focuses on different aspects of aging including the Urinary Incontinence (UI) of elderly women. It is a longitudinal dataset containing a baseline and three follow-up surveys. In this study, we will consider the baseline and the first follow-up. The baseline of MESA is collected in 1983. The investigators surveyed 1957 respondents, 596 of whom were women aged 60 years and older. The respondents were interviewed for approximately 2 hours at home at baseline (1983-1984 interviews) and then re-interviewed at 1-2 year intervals. The respondents are interviewed on a variety of health related questions that may play a role in the prevalence of urinary incontinence (UI). The class labels of the MESA data are 'continent' and 'incontinent' indicating the respondent's outcome. Although, the survey focused on the epidemiology of UI, many other attributes were also assessed including medical history, mobility, cognitive function, current health, and quality of life. The baseline of the MESA dataset contains 34 branching questions which are listed in the paper.

The patients in the MESA dataset are stratified into different populations based on each branching question. A statistical method is used to determine the significant branching questions, i.e. the branching questions that split the dataset into two significantly diverse populations. Once the two sub-populations are explored, the index estimation and the risk factor analyses can be performed on those populations.

This paper is organized as follows: In Section 2 the statistical method of identifying significant branching questions is examined. Section 3 describes the validation for the simulated data. Section 4 presents the results for the simulated data and the MESA data along with the risk factor analyses on each stratum. Finally, Section 5 presents our conclusion and future work. 
International Journal of Data Mining \& Knowledge Management Process (IJDKP) Vol.4, No.4, July 2014

\section{METHOD}

Fisher's Exact Test is a statistical significance test used in the analysis of contingency tables. It is used for all sample sizes. The significance of the deviation from a null hypothesis can be calculated exactly. Therefore, it is not necessary to rely on an approximation that becomes exact in the limit as the sample size grows to infinity. The Fisher's Exact Test is used to determine if there are nonrandom associations between the two variables.

As mentioned before, the dataset is divided into sub populations $\left(\right.$ Branch $_{1}$, Branch $\left._{2}\right)$ based on each branching question. Even though, this method can be applied on each question, we limit the number of tests we are using by the branching questions for the following reason: when dividing the population into subgroups, the split is induced by a threshold which is determined by the expert knowledge for each branching question. However, for each non-branching question determining a threshold for each type of answer (categorical, binary, numeric) may lead to incorrect classifications.

Table 1 shows a contingency table where the $\mathrm{p}$ values are calculated by the following formula:

$$
P=\frac{\left(\left(\begin{array}{c}
\boldsymbol{a}+\boldsymbol{b} \\
\boldsymbol{a}
\end{array}\right)\left(\begin{array}{c}
\boldsymbol{c}+\boldsymbol{d} \\
\boldsymbol{c}
\end{array}\right)\right)}{\left(\begin{array}{c}
\boldsymbol{n} \\
\boldsymbol{a}+\boldsymbol{c}
\end{array}\right)}=\frac{(a+b) !(c+d) !(a+c) !(b+d) !}{a ! b ! c ! d ! n !}
$$

Here, $R_{1}, R_{2}$, and $R_{3}$ are association rules extracted from datasets Branch $_{1}$ or Branch $_{2}$. The values $a, b, c$ and $d$ are the number of subjects that support/contradict the extracted rules in those two datasets. A different contingency table needs to be generated for each branching question.

Since MESA dataset contains 1957 subjects, the high values used in the formula above resulted in computational considerations. Therefore, the Fisher's Exact Test calculation is modified as shown below.

Table 1 - Contingency Table for Stratification

\begin{tabular}{|c|c|c|c|c|}
\hline & & Branch $_{1}$ & Branch $_{2}$ & Row Total \\
\hline \multirow[t]{3}{*}{$R_{1}$} & $\#$ of subjects that support $R_{1}$ & $a$ & $b$ & $a+b$ \\
\hline & $\#$ of subjects that contradict $R_{1}$ & $c$ & $d$ & $c+d$ \\
\hline & Column Total & $a+c$ & $b+d$ & $a+b+c+d$ \\
\hline $\boldsymbol{R}_{2}$ & $\begin{array}{l}\text { \# of subjects that support } R_{2} \\
\text { \# of subjects that contradict } R_{2}\end{array}$ & & & \\
\hline ... & $\cdots$ & & & \\
\hline $\boldsymbol{R}_{n}$ & $\begin{array}{l}\text { \# of subjects that support } R_{n} \\
\text { \# of subjects that contradict } R_{n}\end{array}$ & & & \\
\hline
\end{tabular}

Input $=$ one variable $x-2 x 2$ data matrix

$K n=\operatorname{sum}(x, 2) ; \operatorname{Sn}=\operatorname{sum}(x) ; N=\operatorname{sum}(K n)$;

$\%$ Rearrange the three matrices if it is necessary. 
International Journal of Data Mining \& Knowledge Management Process (IJDKP) Vol.4, No.4, July 2014

$\operatorname{sort}(K n)$

$\operatorname{sort}(\mathrm{Sn})$

$\%$ Generate the following loop.

index $=0: 1: \min (\operatorname{Kn}(1), \operatorname{Sn}(1))$

$$
\begin{aligned}
& z=[\text { index } ; K n(2)-S n(1)+\text { index } ; K n(1)-i n d e x ; S n(1)-i n d e x ;] \\
& n p=\operatorname{zeros}(1, \operatorname{length}(\text { index })) ; \operatorname{lz}=\log (z) \\
& \% \text { Use the gammaln() function to reduce the computational complexity } \\
& n p(1)=\operatorname{sum}(\operatorname{gammaln}([K n(2)+1 \operatorname{Sn}(2)+1])-\operatorname{gammaln}([N+1 z(2)+1])) \\
& f=\operatorname{sum}(l z(3: 4,1: \text { end }-1))-\operatorname{sum}(l z(1: 2,2: \text { end })) \\
& n p(2: e n d)=n p(1)+\operatorname{cumsum}(f) \\
& \% \exp () \text { used because of gammaln() } \\
& n p=\exp (n p) ; W=x(1)+1 \\
& \% \text { then compute the } p \text {-values } \\
& \text { Pvalue }=[P 0.5 * n p(W)+\operatorname{sum}(n p(n p<n p(W)))]
\end{aligned}
$$

Algorithm 1- Fisher's Exact Test

\section{SIMULATION}

The simulation is created by generating two independent binary datasets. The first dataset $D_{1}$ and the second dataset $D_{2}$ both contain 1000 subjects where $S_{1}=\left\{S_{11}, S_{21}, S_{31}, \ldots, S_{1000}\right\}$ is the subject set of $D_{1}$ and $S_{2}=\left\{S_{12}, S_{22}, S_{32}, \ldots, S_{10002}\right\}$ is the subject set of $D_{2}$ and 15 common attributes $\left(A=\left\{A_{1}, A_{2}, A_{3}, \ldots, A_{15}\right\}\right)$. Three different rules are embedded to each dataset. The rules are generated in the sense that none of the rules contradict with another rule. There is no attribute being used in more than one rule. The class labels contain both the classes from the baseline and the first follow up. ' $C-I$ ' is an example of a response indicating that the subject was continent in the baseline and became incontinent in the first follow-up. The rules that are embedded to $D_{l}$ are as follows:

$R_{11}=A 1=0 \& A 3=1 \Rightarrow I-C$

$R_{21}=A 5=0 \& A 7=1 \Rightarrow C-I$

$R_{31}=A 10=1 \& A 12=1 \Rightarrow C-I$

The rules that are embedded to $D_{2}$ are as follows:

$R_{12}=A 2=0 \& A 11=0 \Rightarrow C-I$

$R_{22}=A 4=1 \& A 9=0 \Rightarrow C-I$

$R_{32}=A 6=0 \& A 8=1 \Rightarrow I-C$

The two datasets are then combined. The combination $\left(D_{1}+D_{2}\right)$, have 2000 subjects $S_{D_{1}+D_{2}}=$ $\left\{S_{11}, S_{21}, S_{31}, \ldots, S_{10001}, S_{12}, S_{22}, S_{32}, \ldots, S_{10002}\right\}$ and 15 attributes $\left(A=\left\{A_{1}, A_{2}, A_{3}, \ldots, A_{15}\right\}\right)$. Three attributes are then added to the combined dataset. Those attributes each represent a branching question having binary values. First branching question $B Q_{1}$, takes value ' 0 ' for each subject existing in $D_{1}$ and value ' 1 ' for each subject existing in $D_{2}$. The second and third branching questions, $B Q_{2}$ and $B Q_{3}$ take random binary values. 
International Journal of Data Mining \& Knowledge Management Process (IJDKP) Vol.4, No.4, July 2014

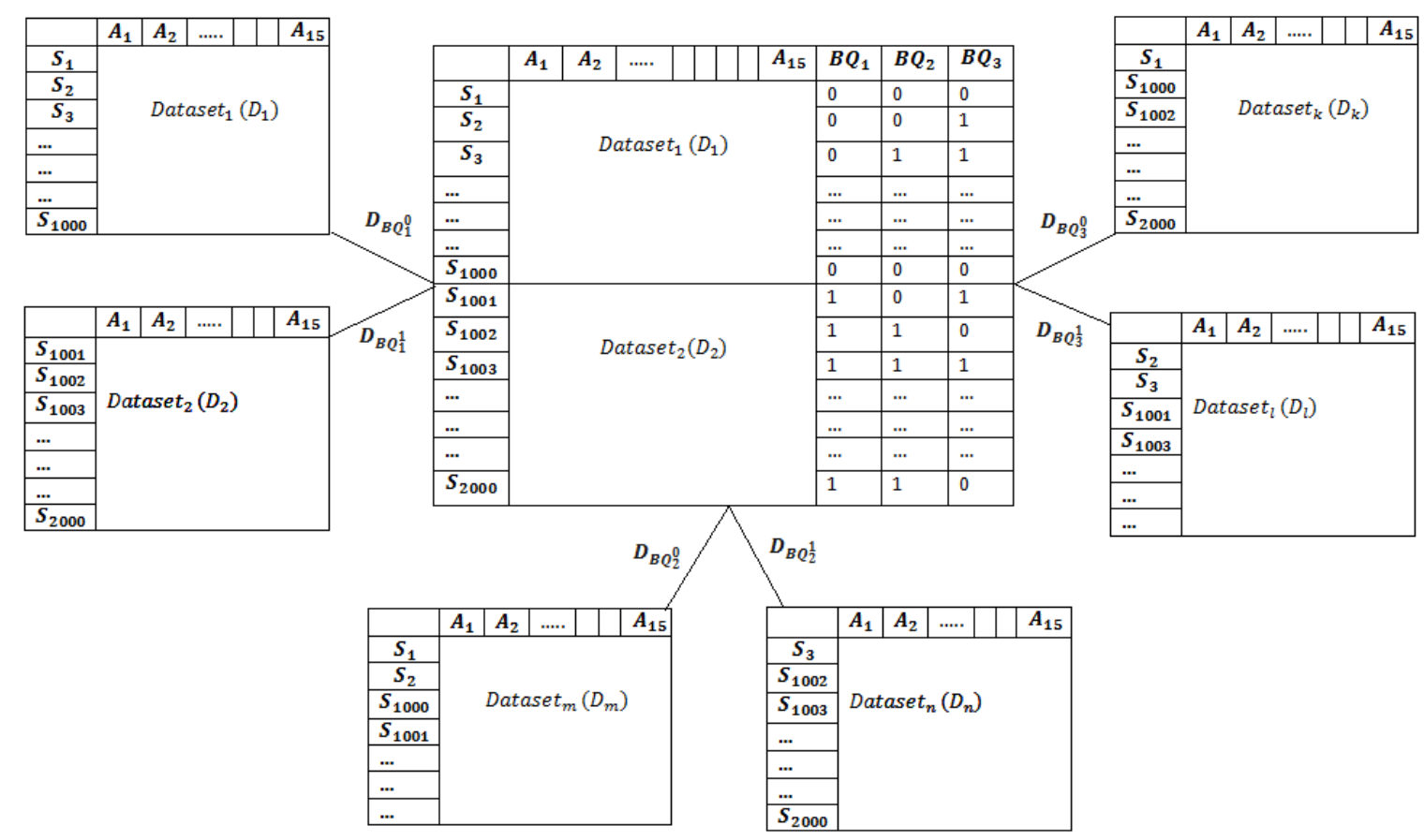

Figure 1- Simulation of Stratification

The combined dataset is then separated into two subsets based on the values of each branching question. The subset for $B Q_{1}$ taking value ' 0 ' is $D_{B Q_{1}^{0}}$ and the subset for $B Q_{1}$ taking value ' 1 ' is $D_{B Q_{1}^{1}}$, similarly the subsets for $B Q_{2}$ are $D_{B Q_{2}^{0}}$ and $D_{B Q_{2}^{1}}$ and the subsets for $B Q_{3}$ are $D_{B Q_{3}^{0}}$ and $D_{B Q_{3}^{1}}$. Figure 1 shows an example of the combined dataset with branching questions that are separated.

The association rule mining algorithm, Apriori, is used to extract the rules of each subset. Apriori is an association rule that iteratively reduces the minimum support until it finds the required number of rules with the given minimum confidence (W. Cohen). Once the rules are extracted for each subset, a contingency table is created for each branching question. A contingency table is a matrix format that displays the frequency distribution of the variables. The rows of the contingency table denote the rules associated with that branching question. The columns are the subsets. For example, for $B Q_{2}$, the rows of the contingency table are the rules extracted from subset $\boldsymbol{D}_{\boldsymbol{B} \boldsymbol{Q}_{2}^{\mathbf{0}}}$ and $\boldsymbol{D}_{\boldsymbol{B} \boldsymbol{Q}_{2}^{\mathbf{1}}}$, respectively. The columns are the datasets $\boldsymbol{D}_{\boldsymbol{B} \boldsymbol{Q}_{2}^{\mathbf{0}}}$ and $\boldsymbol{D}_{\boldsymbol{B} \boldsymbol{Q}_{2}^{\mathbf{1}}}$. The contingency table is created to display the relative frequencies, i.e. the support/no support of each rule for each subset.

Once the contingency table is created, the p-values are calculated using the Fisher's Exact Test explained in the Methods Section. Based on the p-values that are calculated, we can determine the branching questions that are statistically significant.

A branching question is a good stratifying factor when it is statistically significant, since different rules (hence different risk factors and predictive factors) are extracted from its sub populations. Therefore, those two sub populations cannot be treated the same. If data is not stratified into sub populations when the branching question is determined to be significant, one may skip some important risk factors and predictive factors. 
International Journal of Data Mining \& Knowledge Management Process (IJDKP) Vol.4, No.4, July 2014

\section{RESULTS}

\subsection{Simulation Results of Stratification}

The contingency tables for three branching questions for the simulated study are analyzed. Table 2 shows the simulation results of stratification with no noise. As mentioned before, the first three rules $\left(R_{11}, R_{21}, R_{31}\right)$ are extracted from the dataset that contains the subjects that have $B Q_{1}^{1}=0$, denoted by $D_{B Q_{1}^{1}}$, and the last three rules $\left(R_{12}, R_{22}, R_{32}\right)$ are extracted from the dataset that contains the subjects that have $B Q_{1}^{2}=1$, denoted by $D_{B Q_{1}^{2}}$. Since the first branching question, $B Q_{1}$, was designed to separate datasets $D_{1}$ and $D_{2}$, it is expected to extract the same rules listed in Section $3\left(R_{11}, R_{21}, R_{31}\right.$ and $\left.R_{12}, R_{22}, R_{32}\right)$ for subsets, $D_{B Q_{1}^{1}}$ and $D_{B Q_{1}^{2}}$. The rules extracted from $D_{B Q_{1}^{1}}$ are the same as the rules extracted from $D_{1}$, and the rules extracted from $D_{B Q_{1}^{2}}$ are the same as the rules extracted from $D_{2}$. Note that, the support of the first three rules $\left(R_{11}, R_{21}, R_{31}\right)$ of dataset $D_{B Q_{1}^{1}}$, is much higher than the support of the first three rules $\left(R_{11}, R_{21}, R_{31}\right)$ of dataset $D_{B Q_{1}^{2}}$ and the non-support of the first three rules $\left(R_{11}, R_{21}, R_{31}\right)$ of dataset $D_{B Q_{1}^{1}}$ is equal to 0 . The reason of the non-support being 0 is that, the rules are generated in the sense that none of the rules contradict with any other. Likewise, for the second branch, $B Q_{1}^{2}$, we expect to see a lower support and a higher nonsupport compared to $B Q_{1}^{1}$, for the first three rules. Notice that, for the last three rules the support of $B Q_{1}^{2}$ is higher than $B Q_{1}^{1}$ and the nonsupport of $B Q_{1}^{2}$ is lower than $B Q_{1}^{1}$, since the last three rules were extracted from $D_{2}$.

Table 2- Significant Branching (OB) p-values for 0\% Noise

\begin{tabular}{|c|c|c|c|c|c|}
\hline Association Rules & Noise: $0 \%$ & $D_{B Q_{1}^{0}}$ & $D_{B Q_{1}^{1}}$ & $\begin{array}{l}\text { Row } \\
\text { T. }\end{array}$ & p-value \\
\hline \multirow{3}{*}{ 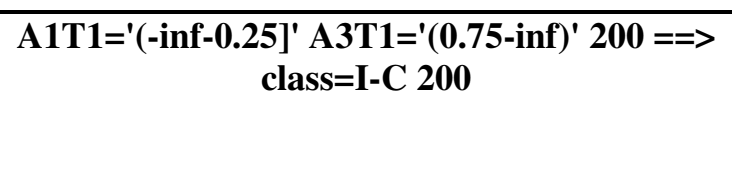 } & Support & 200 & 17 & 217 & \multirow[t]{3}{*}{$3.224 \mathrm{e}^{-46}$} \\
\hline & No Support & 0 & 61 & 61 & \\
\hline & $\begin{array}{l}\text { Column } \\
\text { Total }\end{array}$ & 200 & 78 & 556 & \\
\hline \multirow{2}{*}{$\begin{array}{c}\text { A5T1='(-inf-0.25]' A7T1 } 1=\text { '(0.75-inf)' } 200==> \\
\text { class }=C-I\end{array}$} & Support & 200 & 31 & 231 & \multirow[t]{2}{*}{$3.730 \mathrm{e}^{-25}$} \\
\hline & $\begin{array}{l}\text { No Support } \\
\text { Column } \\
\text { Total }\end{array}$ & $\begin{array}{l}0 \\
200\end{array}$ & $\begin{array}{l}34 \\
65\end{array}$ & $\begin{array}{l}34 \\
\mathbf{5 3 0}\end{array}$ & \\
\hline \multirow{2}{*}{$\begin{array}{c}\text { A10T1='(0.75-inf)' A12T1 ='(0.75-inf })^{\prime} 200 \\
==>\text { class }=C-I 200\end{array}$} & Support & 200 & 33 & 233 & \multirow[t]{2}{*}{$7.54 \mathrm{e}^{-30}$} \\
\hline & $\begin{array}{l}\text { No Support } \\
\text { Column } \\
\text { Total }\end{array}$ & $\begin{array}{l}0 \\
200\end{array}$ & $\begin{array}{l}43 \\
76\end{array}$ & $\begin{array}{l}43 \\
\mathbf{5 5 2}\end{array}$ & \\
\hline \multirow{2}{*}{$\begin{array}{c}\text { A2T1='(-inf-0.25]' A11T1='(-inf-0.25]' } 200 \\
==>\text { class }=\text { C-I } 200\end{array}$} & Support & 26 & 200 & 226 & \multirow[t]{2}{*}{$4.92 \mathrm{e}^{-29}$} \\
\hline & $\begin{array}{l}\text { No Support } \\
\text { Column } \\
\text { Total }\end{array}$ & $\begin{array}{l}38 \\
64\end{array}$ & $\begin{array}{l}0 \\
200\end{array}$ & $\begin{array}{l}38 \\
\mathbf{5 2 8}\end{array}$ & \\
\hline \multirow{2}{*}{$\begin{array}{c}\text { A4T1 }=(0.75-\text { inf })^{\prime} \text { A9T1 } 1='(- \text { inf }-0.25]^{\prime} 200==> \\
\text { class }=C-I 200\end{array}$} & Support & 28 & 200 & 228 & \multirow[t]{2}{*}{$1.30 \mathrm{e}^{-29}$} \\
\hline & $\begin{array}{l}\text { No Support } \\
\text { Column } \\
\text { Total }\end{array}$ & $\begin{array}{l}40 \\
68\end{array}$ & $\begin{array}{l}0 \\
200\end{array}$ & $\begin{array}{l}40 \\
536\end{array}$ & \\
\hline
\end{tabular}


International Journal of Data Mining \& Knowledge Management Process (IJDKP) Vol.4, No.4, July 2014

\begin{tabular}{clllll}
\hline A6T1='(-inf-0.25]' A8T1='(0.75-inf)' & 200 ==> \\
class=I-C 200 & Support & 10 & 200 & 210 & $2.74 \mathrm{e}^{-37}$ \\
& No Support & 40 & 0 & 40 & \\
& $\begin{array}{l}\text { Column } \\
\text { Total }\end{array}$ & 50 & 200 & $\mathbf{5 0 0}$ & \\
& & & & \\
\hline
\end{tabular}

The p-values are calculated and the results show that, for each rule, the association between the rules and two populations are considered to be extremely statistically significant. Therefore, we can define, $B Q_{1}$, as a significant branching question. That means, the two populations, $B Q_{1}^{1}$ and $B Q_{1}^{2}$ has different association rules hence; they have to be analyzed separately.

Table 3, 4, and 5 show the same experiment with $10 \%, 20 \%$ and $30 \%$ noise, respectively. Note that, even if there is $30 \%$ noise in the data, the p-values are still considered to be very statistically significant. However, the comparison of the p-values with different noise levels also show that, the p-values become less significant when the noise level increases.

Table 3- Significant Branching (OB) p-values for 10\% Noise

\begin{tabular}{|c|c|c|c|c|c|}
\hline Association Rules & $\begin{array}{l}\text { Noise: } \\
10 \%\end{array}$ & $D_{B Q_{1}^{0}}$ & $D_{B Q_{1}^{1}}$ & Row T. & p-value \\
\hline \multirow{4}{*}{ 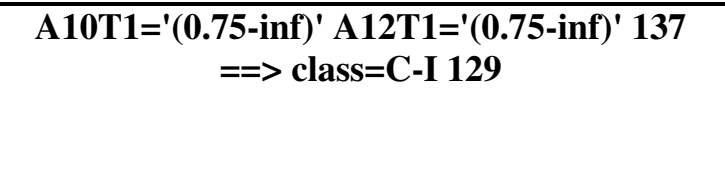 } & Support & 129 & 16 & 145 & \multirow[t]{4}{*}{$3.02 \mathrm{e}^{-17}$} \\
\hline & NoSupport & 8 & 33 & 41 & \\
\hline & Column & 137 & 49 & 372 & \\
\hline & Total & & & & \\
\hline \multirow{4}{*}{$\begin{array}{c}\text { A5T1 }=\text { '(-inf-0.25]' A7T1 } 1='(0.75-\text { inf })^{\prime} 146==> \\
\text { class }=C-I\end{array}$} & Support & 135 & 24 & 159 & \multirow[t]{3}{*}{$3.94 \mathrm{e}^{-14}$} \\
\hline & NoSupport & 11 & 34 & 45 & \\
\hline & Column & 146 & 58 & 408 & \\
\hline & $\begin{array}{l}\text { Total } \\
\text { Support }\end{array}$ & 129 & 7 & 136 & \multirow{3}{*}{$1.57 \mathrm{e}^{-33}$} \\
\hline \multirow{2}{*}{$\begin{array}{c}\text { A1T1='(-inf-0.25]' A3T1='(0.75-inf)' } 143==> \\
\text { class }=\text { I-C } 129\end{array}$} & NoSupport & 14 & 67 & 81 & \\
\hline & $\begin{array}{l}\text { Column } \\
\text { Total }\end{array}$ & 143 & 74 & 434 & \\
\hline \multirow{3}{*}{$\begin{array}{c}\text { A4T1='(0.75-inf)' A9T1='(-inf- }-0.25]^{\prime} 150==> \\
\text { class=C-I } 140\end{array}$} & Support & 26 & 140 & 166 & \multirow[t]{3}{*}{$2.70 \mathrm{e}^{-15}$} \\
\hline & NoSupport & 36 & 10 & 46 & \\
\hline & $\begin{array}{l}\text { Column } \\
\text { Total }\end{array}$ & 62 & 150 & 424 & \\
\hline \multirow{3}{*}{$\begin{array}{c}\text { A6T1='(-inf-0.25]' A8T1='(0.75-inf)' } 147==> \\
\text { class }=I-C 135\end{array}$} & Support & 12 & 135 & 147 & \multirow[t]{6}{*}{$5.12 \mathrm{e}^{-23}$} \\
\hline & NoSupport & 45 & 12 & 57 & \\
\hline & $\begin{array}{l}\text { Column } \\
\text { Total }\end{array}$ & 57 & 147 & 408 & \\
\hline \multirow{3}{*}{$\begin{array}{c}\text { A2T1='(-inf-0.25]' A11T1='(-inf- }-0.25]^{\prime} 155 \\
==>\text { class }=C-I 141\end{array}$} & Support & 18 & 141 & 159 & \\
\hline & NoSupport & 35 & 14 & 49 & \\
\hline & $\begin{array}{l}\text { Column } \\
\text { Total }\end{array}$ & 53 & 155 & 416 & \\
\hline
\end{tabular}


International Journal of Data Mining \& Knowledge Management Process (IJDKP) Vol.4, No.4, July 2014

Table 4- Significant Branching (OB) p-values for $20 \%$ Noise

\begin{tabular}{|c|c|c|c|c|c|}
\hline Association Rules & Noise: $20 \%$ & $D_{B Q_{1}^{0}}$ & $D_{B Q_{1}^{1}}$ & Row T. & p-value \\
\hline \multirow[t]{4}{*}{ A5T1='(-inf-0.25]' 169==> class=C-I 126} & Support & 126 & 54 & 180 & \multirow[t]{4}{*}{$4.47 \mathrm{e}^{-9}$} \\
\hline & No Support & 43 & 78 & 121 & \\
\hline & Column & 169 & 132 & 602 & \\
\hline & Total & & & & \\
\hline \multirow{4}{*}{$\begin{array}{c}\text { A5T1='(-inf-0.25]' A7T1='(0.75-inf)' } 173==> \\
\text { class }=C-I 128\end{array}$} & Support & 128 & 59 & 187 & \multirow[t]{4}{*}{$3.80 \mathrm{e}^{-9}$} \\
\hline & No Support & 45 & 84 & 129 & \\
\hline & Column & 173 & 143 & 632 & \\
\hline & Total & & & & \\
\hline \multirow{4}{*}{$\begin{array}{c}\mathrm{A} 5 \mathrm{~T} 1=^{\prime}(-\mathrm{inf}-0.25]^{\prime} \mathrm{A} 7 \mathrm{~T} 11^{\prime}(\mathbf{0 . 7 5}-\mathrm{inf})^{\prime} \quad 173==> \\
\text { class }=\mathrm{C}-\mathrm{I} 124\end{array}$} & Support & 124 & 54 & 178 & \multirow[t]{4}{*}{$4.93 \mathrm{e}^{-7}$} \\
\hline & No Support & 49 & 73 & 122 & \\
\hline & Column & 173 & 127 & 600 & \\
\hline & $\begin{array}{l}\text { Total } \\
\text { Support }\end{array}$ & 46 & 114 & 160 & \\
\hline \multirow{2}{*}{$\begin{array}{c}\text { A2T1='(-inf-0.25]' A11T1='(-inf-0.25]' } 149 \\
==>\text { class=C-I } 114\end{array}$} & No Support & 68 & 35 & 103 & \multirow{2}{*}{$3.06 \mathrm{e}^{-y}$} \\
\hline & Column & 114 & 149 & 526 & \\
\hline \multirow{3}{*}{$\begin{array}{c}\text { A4T1='(0.75-inf)' A9T1='(-inf-0.25]' } 151==> \\
\text { class }=C-I 115\end{array}$} & Support & 42 & 115 & 157 & \multirow[t]{3}{*}{$4.96 \mathrm{e}^{-15}$} \\
\hline & No Support & 96 & 36 & 132 & \\
\hline & Column & 138 & 151 & 578 & \\
\hline \multirow[t]{3}{*}{ A11T1='(-inf-0.25]' $161==>$ class $=$ C-I 122} & Support & 43 & 122 & 165 & \multirow[t]{3}{*}{$1.36 \mathrm{e}^{-13}$} \\
\hline & No Support & 83 & 39 & 122 & \\
\hline & $\begin{array}{l}\text { Column } \\
\text { Total }\end{array}$ & 126 & 161 & 574 & \\
\hline
\end{tabular}

Table 5- Significant Branching (OB) p-values for 30\% Noise

\begin{tabular}{|c|c|c|c|c|c|}
\hline Association Rules & Noise:30\% & $D_{B Q_{1}^{0}}$ & $D_{B Q_{1}^{1}}$ & Row T. & p-value \\
\hline \multirow[t]{4}{*}{ A12T1='(0.75-inf)' $263==>$ class $=C-I 150$} & Support & 150 & 105 & 255 & \multirow[t]{4}{*}{0.0018} \\
\hline & No Support & 113 & 139 & 252 & \\
\hline & Column & 263 & 244 & 1014 & \\
\hline & Total & & & & \\
\hline \multirow{4}{*}{$\begin{array}{l}\left.\text { A10T1 } 1=(0.75 \text {-inf })^{\prime} \text { A12T1='(0.75-inf }\right)^{\prime} 257 \\
==>\text { class }=C \text {-I } 143\end{array}$} & Support & 143 & 90 & 233 & \multirow[t]{4}{*}{$7.24 \mathrm{e}^{-005}$} \\
\hline & No Support & 114 & 149 & 263 & \\
\hline & Column & 257 & 239 & 992 & \\
\hline & Total & & & & \\
\hline \multirow[t]{4}{*}{ A4T1 $1=(0.75 \text {-inf })^{\prime} 249==>$ class $=C-I 145$} & Support & 96 & 145 & 241 & \multirow[t]{4}{*}{$4.69 \mathrm{e}^{-005}$} \\
\hline & No Support & 146 & 104 & 250 & \\
\hline & Column & 242 & 249 & 982 & \\
\hline & Total & & & & \\
\hline \multirow[t]{3}{*}{ A9T1='(-inf -0.25$]^{\prime} 269==>$ class $=C-I 152$} & Support & 81 & 152 & 233 & \multirow[t]{3}{*}{$7.62 \mathrm{e}^{-005}$} \\
\hline & No Support & 131 & 117 & 248 & \\
\hline & $\begin{array}{l}\text { Column } \\
\text { Total }\end{array}$ & 212 & 269 & 962 & \\
\hline
\end{tabular}


International Journal of Data Mining \& Knowledge Management Process (IJDKP) Vol.4, No.4, July 2014

Table 6 shows the contingency table for the second branching question, $B Q_{2}$. As mentioned before, the binary values of the second branching question were assigned randomly, and based on the binary values $B Q_{2}$ have, the combined dataset $\left(D_{1}+D_{2}\right)$ is separated into $D_{B Q_{2}^{0}}$ and $D_{B Q_{2}^{1}}$.

Since $B Q_{2}$ values are assigned randomly, once separated, $D_{B Q_{2}^{0}}$ and $D_{B Q_{2}^{1}}$ datasets each may contain subjects from both $D_{1}$ and $D_{2}$. Therefore, the rule extraction technique will extract the rules or some attributes within the rules belonging to both $D_{1}$ and $D_{2}$ for each of the separated data. As a result, the rules will be corrupted and therefore the support of each extracted rule will decrease compared to the significant branching example given before.. Table 6 shows that the association between the rules and the population is considered to be not statistically significant. Table 7 shows the results with $10 \%$ noise where the p-values increase. Therefore, $B Q_{2}$ is not considered as a significant branching question.

Table 6- Bad Branching (BB) p-values for $0 \%$ Noise

\begin{tabular}{|c|c|c|c|c|c|}
\hline Association Rules & Noise: $0 \%$ & $D_{B Q_{2}^{0}}$ & $D_{B Q_{2}^{1}}$ & Row T. & p-value \\
\hline \multirow{3}{*}{$\begin{array}{c}\text { A4T1='(0.75-inf)' A9T1='(-inf-0.25]' } 136 \\
==>\text { class }=\text { C-I } 117\end{array}$} & Support & 117 & 111 & 128 & \multirow[t]{3}{*}{0.7326} \\
\hline & No Support & 19 & 21 & 40 & \\
\hline & Column $\mathbf{T}$. & 136 & 132 & 436 & \\
\hline \multirow{4}{*}{$\begin{array}{c}\text { A2T1='(-inf-0.25]' A11T1='(-inf-0.25]' } 132 \\
==>\text { class }=\text { C-I } 112\end{array}$} & Support & 112 & 114 & 226 & \multirow[t]{4}{*}{0.8610} \\
\hline & No Support & 20 & 18 & 38 & \\
\hline & Column & 132 & 132 & 528 & \\
\hline & Total & & & & \\
\hline \multirow{3}{*}{$\begin{array}{c}\text { A5T1='(-inf-0.25]' A7T1='(0.75-inf)' } 124 \\
==>\text { class }=\text { C-I } 107\end{array}$} & Support & 124 & 107 & 231 & \multirow[t]{3}{*}{0.7160} \\
\hline & No Support & 17 & 17 & 34 & \\
\hline & Column & 141 & 124 & 530 & \\
\hline \multirow{3}{*}{$\begin{array}{c}\text { A10T1='(0.75-inf)' A12T1='(0.75-inf)' } 123 \\
==>\text { class }=C-I 109\end{array}$} & Total & 124 & 109 & 233 & \multirow{3}{*}{0.0962} \\
\hline & No Support & 29 & 14 & 43 & \\
\hline & $\begin{array}{l}\text { Column } \\
\text { Total }\end{array}$ & 153 & 123 & 552 & \\
\hline
\end{tabular}

Table 7- Bad Branching (BB) p-values for 10\% Noise

\begin{tabular}{|c|c|c|c|c|c|}
\hline Association Rules & Noise: $10 \%$ & $D_{B Q_{2}^{0}}$ & $D_{B Q_{2}^{1}}$ & Row $T$. & p-value \\
\hline \multirow{4}{*}{$\begin{array}{c}\text { A4T1='(0.75-inf)' A9T1='(-inf-0.25]' } 152 \\
==>\text { class }=\text { C-I } 109\end{array}$} & Support & 109 & 109 & 218 & 0.3932 \\
\hline & No Support & 43 & 54 & 97 & \\
\hline & Column & 152 & 163 & 630 & \\
\hline & Total & & & & \\
\hline \multirow{4}{*}{$\begin{array}{c}\left.\text { A10T1='(0.75-inf })^{\prime} \text { A12T1='(0.75-inf }\right)^{\prime} 158 \\
==>\text { class }=C-I 108\end{array}$} & Support & 108 & 87 & 315 & 0.4590 \\
\hline & No Support & 50 & 49 & 99 & \\
\hline & Column & 158 & 136 & 708 & \\
\hline & Total & & & & \\
\hline \multirow{3}{*}{ A4T1='(0.75-inf)' $156==>$ class=C-I 106} & Support & 106 & 97 & 203 & 0.4721 \\
\hline & No Support & 50 & 55 & 105 & \\
\hline & $\begin{array}{l}\text { Column } \\
\text { Total }\end{array}$ & 156 & 152 & 616 & \\
\hline
\end{tabular}


International Journal of Data Mining \& Knowledge Management Process (IJDKP) Vol.4, No.4, July 2014

\begin{tabular}{|c|c|c|c|c|c|}
\hline \multirow{4}{*}{$\begin{array}{c}\text { A5T1='(-inf-0.25]' A7T1='(0.75-inf)' } 159 \\
==>\text { class }=\text { C-I } 110\end{array}$} & Support & 96 & 110 & 206 & 0.3361 \\
\hline & No Support & 55 & 49 & 104 & \\
\hline & Column & 151 & 159 & 620 & \\
\hline & $\begin{array}{l}\text { Total } \\
\text { Support }\end{array}$ & 104 & 102 & 206 & 1.0000 \\
\hline A2T1='(-inf-0.25]' A11T1='(-inf-0.25]' 152 & No Support & 52 & 50 & 102 & \\
\hline$==>$ class $=$ C $-\mathrm{I} 102$ & Column T. & 156 & 152 & 616 & \\
\hline
\end{tabular}

As a result, $B Q_{1}$ was defined as a significant stratifying factor that divides the dataset into two populations with different extracted rules, whereas $B Q_{2}$ and $B Q_{3}$ are not significant factors. Hence, this simulation validates that the Fisher's Exact Test can be used to determine the significant branching questions.

\subsubsection{MESA Results of Stratification}

The same experiment is then applied on the MESA dataset. The branching questions that are extracted from the MESA data are the following:

Table 8- List of Branching Questions

\begin{tabular}{ll}
\hline Label & Branching Questions \\
\hline $\mathbf{v 3 2}$ & Are you married, widowed, divorced, separated, or have you never married? \\
$\mathbf{v 4 1}$ & Do you sneeze often, sometimes, rarely or never? \\
$\mathbf{v 5 3}$ & Do you usually need to use a wheelchair, cane, crutches or walker to help you get around? \\
$\mathbf{v 5 9}$ & Do you have any health problems which make it difficult for you to leave your home and go \\
& visiting, shopping, or to the doctor's? \\
$\mathbf{v 8 7}$ & Have you ever been told by a doctor that you had high blood pressure? \\
$\mathbf{v 9 0}$ & Have you ever been told by a doctor that you had a hernia in the groin or stomach area? \\
$\mathbf{v 9 2}$ & Have you ever had a stroke or cerebral brain hemorrhage? \\
$\mathbf{v 9 5}$ & Have you ever been told by a doctor that you occasionally have had transient ischemic \\
& attacks or poor blood flow to the brain, where you seem to lose track of things that are \\
$\mathbf{v} 97$ & happening around you for up to a few minutes? \\
$\mathbf{v 1 0 7}$ & Have you ever had problems with any paralysis? \\
$\mathbf{v 1 1 1}$ & Has any doctor ever told you that you have or have had arthritis or rheumatism? \\
$\mathbf{v 1 2 5}$ & Have you had any other disease of the nerves or muscles? \\
$\mathbf{v 1 2 8}$ & Have you ever been told by a doctor that you had cancer of any kind? \\
$\mathbf{v 1 3 3}$ & Have you lost any inches in height as you have gotten older? \\
$\mathbf{v 1 3 5}$ & In the last 12 months how many times have you become so dizzy that you fainted or nearly \\
& fainted? \\
$\mathbf{v} 138$ & Have you broken any bones in the last 12 months? \\
$\mathbf{v 1 7 1}$ & How many pregnancies have you had? \\
$\mathbf{v 1 8 0}$ & Have you ever had female surgery such as on your ovaries, vagina, fallopian tubes, uterus, \\
& rectum, or urethra? \\
$\mathbf{v} 193$ & Are you currently taking any female hormones? \\
$\mathbf{v 2 0 7}$ & Have you ever had any other operations on your bladder, kidneys, or any other organs in \\
$\mathbf{v} 219$ & your pelvic area or area normally covered by underpants or undershorts? \\
$\mathbf{v 2 2 0}$ & Do you usually need help in getting into the bathroom or on or off of the toilet? \\
& the toilet in your home? \\
\hline
\end{tabular}


International Journal of Data Mining \& Knowledge Management Process (IJDKP) Vol.4, No.4, July 2014

v224 Do you have your regular schedule that you usually use to get you to the toilet to urinate, for example every hour or so?

$\mathbf{v 4 1 5}$ Have you ever had or have you been told by a doctor that you had any kidney or bladder problems we haven't talked about already?

v418 Do you usually drink any liquids of any kind before you go to bed at night?

$\mathbf{v 4 2 2}$ Did your mother of father have a urine loss condition as an adult?

$\mathbf{v 4 5 8}$ Do you have any health problems that require medical attention that you have not been able to get treated?

$\mathbf{v 4 9 6}$ As you know some people experience memory problems as they get older. How about your memory? Has it become worse within the last five years?

v540 Have you ever had to stay in a nursing home overnight or longer because of a health problem you had?

$\mathbf{v 5 4 3}$ Have you ever had to stay in a mental health facility overnight or longer, because of a mental or emotional problem that you had?

v725 Do you usually take one or more naps during the day?

v737 Have you smoked at least 100 cigarettes in your entire life?

$\mathbf{v 7 4 5}$ Do you drink wine, beer, or liquor?

v776 Is this the same occupation that you had for most of your life?

The data is stratified based on the branching questions listed above. For many of the branching questions there were not enough subjects for a rule to be generated (ex. not enough female subjects taking female hormones to generate a rule). For those branching questions, a contingency table could not be generated. Table 9 shows the contingency table for the subjects that have undergone female surgery and the ones that have not. The p-values show that the association between the rules and the data is not considered to be statistically significant. Therefore, female surgery cannot be considered as a significant branching question.

Table 9-Contingecy Table of Female Surgery

\begin{tabular}{|c|c|c|c|c|c|}
\hline Female Surgery- Association Rules & & $D_{F S}$ & $D_{N F S}$ & Row T. & p-value \\
\hline $\begin{array}{l}\text { v124='(-inf-0.5]' v152='(-inf-0.5]' v178='(- } \\
\text { inf-0.5]' v195='(-inf-0.5]' v230='(-inf-0.5]' } \\
\text { v231='(-inf-0.5]' } 78==>\text { class=C-C } 49 \\
\text { conf: }(0.63)\end{array}$ & $\begin{array}{l}\text { Support } \\
\text { No Support } \\
\text { Column T. }\end{array}$ & $\begin{array}{l}49 \\
29 \\
78\end{array}$ & $\begin{array}{l}38 \\
29 \\
67\end{array}$ & $\begin{array}{l}87 \\
58 \\
145\end{array}$ & 0.4988 \\
\hline $\begin{array}{l}\text { v120='All' v124='(-inf-0.5]' v152='(-inf- }-0.5]^{\prime} \\
\text { v178='(-inf-0.5]' v195='(-inf-0.5]' v230='(- } \\
\text { inf-0.5]' v231='(-inf-0.5]' } 78==>\text { class=C-C } \\
49 \text { conf: }(0.63)\end{array}$ & $\begin{array}{l}\text { Support } \\
\text { No Support } \\
\text { Column T. }\end{array}$ & $\begin{array}{l}49 \\
29 \\
78\end{array}$ & $\begin{array}{l}38 \\
29 \\
67\end{array}$ & $\begin{array}{l}87 \\
58 \\
145\end{array}$ & 0.4988 \\
\hline $\begin{array}{l}\text { v121='All' v124='(-inf-0.5]' v152='(-inf- } 0.5]^{\prime} \\
\text { v178='(-inf-0.5]' v195='(-inf-0.5]' v230='(- } \\
\text { inf-0.5]' v231='(-inf-0.5]' } 78==>\text { class }=C-C \\
49 \text { conf: }(0.63)\end{array}$ & $\begin{array}{l}\text { Support } \\
\text { No Support } \\
\text { Column T. }\end{array}$ & $\begin{array}{l}49 \\
29 \\
78\end{array}$ & $\begin{array}{l}38 \\
29 \\
67\end{array}$ & $\begin{array}{l}87 \\
58 \\
145\end{array}$ & 0.4988 \\
\hline $\begin{array}{l}\left.\text { v107 }=\text { '(-inf- } 0.5]^{\prime} \text { v125='(-inf- } 0.5\right]^{\prime} \text { v199='(- } \\
\text { inf- }-0.5]^{\prime} \text { v432='(-inf-0.5]' } 67==>\text { class=C-I } \\
43 \text { conf: }(0.64)\end{array}$ & $\begin{array}{l}\text { Support } \\
\text { No Support } \\
\text { Column T. }\end{array}$ & $\begin{array}{l}32 \\
33 \\
65\end{array}$ & $\begin{array}{l}43 \\
24 \\
67\end{array}$ & $\begin{array}{l}75 \\
57 \\
132\end{array}$ & 0.1135 \\
\hline v78='(-inf-0.5]' v107='(-inf-0.5]' v125='(-inf- & Support & 30 & 43 & 73 & \\
\hline
\end{tabular}


International Journal of Data Mining \& Knowledge Management Process (IJDKP) Vol.4, No.4, July 2014

\begin{tabular}{lllllll}
\hline 0.5]' v199='(-inf-0.5]' v432='(-inf-0.5]' 67 & & & & & \\
$==>$ class=C-I 43 conf:(0.64) & No Support & 32 & 24 & $\mathbf{5 6}$ & \\
& Column T. & $\mathbf{6 2}$ & $\mathbf{6 7}$ & $\mathbf{1 2 9}$ & \\
& S107='(-inf-0.5]' v120='All' v125='(-inf-0.5]' & Support & 32 & 43 & $\mathbf{7 5}$ & \\
v199='(-inf-0.5]' v432='(-inf-0.5]' 67 ==> & No Support & 33 & 24 & $\mathbf{5 7}$ & \multirow{2}{*}{$\mathbf{0 . 1 1 3 5}$} \\
class=C-I 43 conf:(0.64) & Column T. & $\mathbf{6 5}$ & $\mathbf{6 7}$ & $\mathbf{1 3 2}$ & \\
\hline
\end{tabular}

Table 10 shows the contingency table for the smokers and non-smokers. Here, the association between the rules and the data is considered to be statistically significant for the rules whose pvalues are underlined in the table. Therefore, smoking is considered to be a significant branching question. Similarly, sneezing and taking naps during the day are significant branching questions in MESA data.

Table 10 - Contingency Table of Smoking

\begin{tabular}{|c|c|c|c|c|c|}
\hline Smoke- Association Rules & & $D_{S}$ & $D_{N S}$ & Row T. & p-value \\
\hline v69='(-inf-0.5]' v80='(-inf-0.5]' v124='(-inf- & Support & 37 & 41 & 78 & \multirow{3}{*}{$\underline{0.0064}$} \\
\hline 0.5$]^{\prime}$ v152='(-inf-0.5]' v230='(-inf-0.5]' 50 & No Support & 13 & 42 & 55 & \\
\hline$==>$ class $=$ C-C 37 conf: $(0.74)$ & Column T. & 50 & 83 & 133 & \\
\hline v69='(-inf- 0.5$]^{\prime}$ v78='(-inf-0.5]' v80='(-inf- & Support & 37 & 41 & 78 & \multirow{3}{*}{$\underline{0.0064}$} \\
\hline 0.5$]^{\prime}$ v124='(-inf-0.5]' v152='(-inf- -0.5$]^{\prime}$ & No Support & 13 & 42 & 55 & \\
\hline $\begin{array}{l}\text { v230 }='(- \text { inf }-0.5]^{\prime} 50==>\text { class }=C-C 37 \\
\text { conf: }(0.74)\end{array}$ & Column T. & 50 & 83 & 133 & \\
\hline v69='(-inf- 0.5$]^{\prime}$ v79='(-inf- 0.5$]^{\prime}$ v80='(-inf- & Support & 37 & 41 & 78 & \multirow{3}{*}{$\underline{0.0064}$} \\
\hline 0.5$]^{\prime}$ v124='(-inf-0.5]' v152='(-inf-0.5]' & No Support & 13 & 42 & 55 & \\
\hline $\begin{array}{l}\text { v } 230==^{\prime}(-\inf -0.5]^{\prime} 50==>\text { class }=C-C 37 \\
\text { conf: }(0.74)\end{array}$ & Column T. & 50 & 83 & 133 & \\
\hline v78='(-inf-0.5]' v107='(-inf-0.5]' v138='(- & Support & 24 & 58 & 82 & \multirow{3}{*}{0.1241} \\
\hline inf -0.5$]^{\prime}$ v432='(-inf -0.5$]^{\prime} 98==>$ class $=C-I$ & No Support & 29 & 40 & 69 & \\
\hline 58 conf: $(0.59)$ & Column T. & 53 & 98 & 151 & \\
\hline \multirow{3}{*}{$\begin{array}{l}\text { v28='(-inf-0.5]' v78='(-inf-0.5]' v79='(-inf- } \\
0.5]^{\prime} \text { v138='(-inf-0.5]' v432='(-inf-0.5]' } 98 \\
==>\text { class=C-I } 58 \text { conf: }(0.59)\end{array}$} & Support & 24 & 58 & 82 & \multirow{3}{*}{$\underline{0.0461}$} \\
\hline & No Support & 34 & 40 & 74 & \\
\hline & Column T. & 58 & 98 & 156 & \\
\hline v78='(-inf-0.5]' v107='(-inf-0.5]' & Support & 24 & 58 & 82 & \multirow{3}{*}{0.1241} \\
\hline v120='All' v138='(-inf- -0.5$]^{\prime}$ v432='(-inf- & No Support & 29 & 40 & 69 & \\
\hline 0.5$]^{\prime} 98==>$ class $=$ C-I 58 conf: $(0.59)$ & Column T. & 53 & 98 & 151 & \\
\hline
\end{tabular}

\subsection{Analysis of the Stratums}

The extracted rules of the significant branching questions can be used for prediction. For example when a new patient comes into the clinic who meets the following rule v69='(-inf- 0.5$]^{\prime}$ v80='(-inf$0.5]^{\prime}$ v124='(-inf-0.5]' v152='(-inf-0.5]' v230='(-inf-0.5]' $50==>$ class $=C-C 37$ conf:(0.74), it can be concluded that, the patient will remain continent with $74 \%$ of probability. 
International Journal of Data Mining \& Knowledge Management Process (IJDKP) Vol.4, No.4, July 2014

Next, the risk factors of different stratums (smokers/non-smokers for our case) need to be determined separately. Relieff attribute selection is used to determine the important attributes of each population, since our previous studies have shown that Relieff outperformed other attribute selection techniques on the analysis of MESA dataset. (Arslanturk et al.). The extracted attributes are defined as the risk factors. Table 11 shows the risk factors for smokers and non-smokers.

Table 11- Risk Factors of Stratums

\begin{tabular}{lll}
\hline & SMOKERS & NON-SMOKERS \\
\cline { 2 - 3 } & v211- Getting yourself wet & v68- Being proud of yourself \\
& $\begin{array}{l}\text { v128- Having Cancer } \\
\text { v229- Difficulties going to the bathroom }\end{array}$ & v128- Having Cancer \\
on time & v719- Having an active hobby \\
v89- Diabetes & v180- Undergone Female Surgery \\
v69- Feeling lonely? & v74- Things are going your way?
\end{tabular}

\section{CONCLUSION AND FUTURE WORK}

The current study models the UI condition on the baseline using stratification based on branching questions. The questionnaire itself may instruct a respondent to skip some not applicable questions (skip patterns) based on the answer to a branching question. Using branching questions to stratify data makes sense as we utilize the wisdom of experts embedded in the data through questionnaire design processes for stratification of data by taking advantage of skip patterns'. The significance of a branching question is determined by the calculated p-values of the Fisher's Exact Test. A branching question is referred as significant, when each stratum returns different rules/risk factors when population is stratified or some risk factors/rules is missed when population is not stratified.

There may be buckets of questions not being answered by some subjects even though they are not constructed as skip patterns. The preceding question of those buckets can be treated as a branching question even though it is a non branching question. The next step of the analysis is to also stratify the population based on those non-branching questions to determine how the risk factors may vary across sub populations.

\section{ACKNOWLEDGMENT}

This work was supported in part by NIH Grant R01AG038673 
International Journal of Data Mining \& Knowledge Management Process (IJDKP) Vol.4, No.4, July 2014

\section{REFERENCES}

[1] A.C. Diokno, B.M. Brock, M.B. Brown, et. al., "Prevalence of urinary incontinence and other urological symptoms in the noninstutionalized elderly," J Urol 1986; 136:1022.

[2] A.C. Diokno, C.M. Sampselle, A.R. Herzog, et. al., "Prevention of urinary incontinence by behavioral modification program: a randomized, controlled trial among older women in the community," J Urol 2004; 171: 1165.

[3] A.C. Diokno, M.B. Brown, B.M. Brock, et. al., "Clinical and cystometric characteristics of continent and incontinent noninstitutionalized elderly," J Urol 1988; 140: 567.

[4] B.Azhagusundari, A.S. Thanamani, "Feature Selection based on Information Gain" International Journal of Innovative Technology and Exploring Engineering (IJITEE), ISSN: 2278-3075, Volume-2, Issue-2, January 2013.

[5] J.Fagan, B. V. Greenberg, "Using Graph Theory to Analyze Skip Patterns in Questionnaires," Bureau of the Census, Statistical Research Division Report Series, SRD Research Report Number: Census/SRD/RR-88/06, 1988.

[6] Lindsey R. Haas, MPH; Paul Y. Takahashi, MD; Nilay D. Shah, PhD; Robert J. Stroebel, MD; Matthew E. Bernard, MD; Dawn M. Finnie, MPA; and James M. Naessens, ScD, "Risk-Stratification Methods for Identifying Patients for Care Coordination”, Am J Manag Care 2013;19(9):725-732

[7] M. A. Hall. "Correlation-based Feature Subset Selection for Machine Learning," Hamilton, New Zealand, 1998

[8] S. Arslanturk, M. R. Siadat, T. Ogunyemi, I. Sethi, A.Diokno. "Comparison of Attribute Selection Techniques Using Fully Controlled Simulation Based Datasets", $2^{\text {nd }}$ International Conference on Information Management and Evaluation 2011, Toronto, Canada

[9] S. Arslanturk, M-R. Siadat, T. Ogunyemi, K. Demirovic, A. Diokno, "Skip Pattern Analysis for Detection of Undetermined and Inconsistent Data", 2012 5th International Conference on BioMedical Engineering and Informatics (BMEI 2012)

[10] W. W. Cohen: "Fast Effective Rule Induction. In: Twelfth International Conference on Machine Learning," 115-123, 1995.

[11] X. Su, C-L. Tsai, H. Wang, D. M. Nickerson, B. Li, "Subgroup Analysis via Recursive Partitioning”, Journal of Machine Learning Research 10 (2009)141-158. 